\title{
RELATIONSHIP OF GREAT CARDIAC VEIN IN THE TRIANGLE OF BROCQ AND MOUCHET- A CORROSION CAST STUDY
}

\section{Suma $H Y^{1}$, Shanthini $S^{2}$.}

${ }^{1}$ Additional Professor, Department of Anatomy, Jawaharlal Institute of Postgraduate Education and Research, Puducherry, India.

${ }^{2}$ Assistant Professor, Department of Anatomy, Sri Lakshmi Narayana Institute of Medical Sciences, Puducherry, India.

\section{ABSTRACT}

Background: The triangle of Brocq and Mouchet is an arteriovenous triangle between the anterior interventricular artery, circumflex artery and the great cardiac vein. The vascular triangle has been classified into 4 types viz. closed, superiorly opened, inferiorly opened and completely opened or absent. Polyurethane foam is a new material used in corrosion casting. It is economical, easy to carry out and does not require special apparatus.

Context and purpose of the study:

a) To study the relationship of the Great cardiac vein (GCV) in the triangle of Brocq and Mouchet in human hearts using PU foam for corrosion cast.

b) To study the relationship of GCV in relation to the arteries forming the triangle.

Results: The triangle was present in $98 \%$ of the hearts. Relationship of GCV in triangle of Brocq and Mouchet: Inferiorly open type of Triangle was the most common (87.5\%). Next common type was, closed type (6.7\%). In relation to GCV relation with the arteries in the triangle, it was to the left of AIA in $87.51 \%$ and crosses circumflex artery, either superficially or deep.

The GCV crossing anterior interventricular artery was found in few specimens. It crossed the artery superficially or deeply. The intertwining type of variation was observed in few casts, and could not be placed under any classification as suggested by previous authors.

Conclusion: The topography of the Great cardiac vein and its variations are significant in relation to the arteries in the region. It is relevant in interventional cardiology, radiology, and catheter-based procedures.

KEY WORDS: Triangle of Brocq And Mouchet, Greater Cardiac Vein, Anterior Interventricular Artery, Anterior Interventricular Groove.

Address for Correspondence: Dr. Suma H Y, Additional Professor, Department of Anatomy, Jawaharlal Institute of Postgraduate Medical Education and Research, Puducherry, India.

Phone-9442550603 E-Mail: suma1478@gmail.com

Access this Article online Quick Response code



DOI: $10.16965 /$ ijar.2019.137

Journal Information

International Journal of Anatomy and Research

ICV for 2016 ISSN (E) 2321-4287 | ISSN (P) 2321-8967

https://www.ijmhr.org/ijar.htm

DOI-Prefix: https://dx.doi.org/10.16965/ijar

Article Information

Received: 05 Feb 2019

Peer Review: 06 Feb 2019

Revised: None
Accepted: 13 Mar 2019

Published (O): 05 Apr 2019

Published (P): 05 Apr 2019

\section{INTRODUCTION}

The triangle of Brocq and Mouchet is an arteriovenous triangle between Anterior interventricular artery (AIA; also called left anterior descending branch in clinical usage, LAD),
Circumflex artery (CXA) and Greater Cardiac Vein (GCV). The above structures are found in between pulmonary trunk and left auricle. The most common course of GCV is located to the left of AIA within the anterior interventricular 
groove. Then it enters the atrioventricular groove, and related superficial to circumflex artery. Here, it forms the base of triangle of Brocq and Mouchet [1]. The floor of the triangle is bounded by myocardium and roof by pericardium with pericardial fluid [2]. The contents of the triangle are the diagonal branches of AIA, which pass either superficial or deep to the vein $[2,3]$. The topography of the structures forming the triangle and their variations have anatomical and surgical implications [1].

It is relevant in interventions in cardiology, interpretations in radiology, and its utility in catheter-based procedures [4].

The vascular triangle has been classified into 4 types, based on arrangement of structures forming its boundaries- closed, superiorly opened, inferiorly opened and completely opened. Sometimes the triangle can be absent $[1,5,6]$.

Bales, 2004 described the intertwined relationship of great cardiac vein, and gave a matrix of possible variations in his literature review [4].

In the present paper, we describe the relationship of GCV with AIA, CXA among South Indian population.

Polyurethane foam is a casting media, which is used in the present study to evaluate the anatomy of coronary veins and arteries. The PU foam is easy to use, polymerizes from foam to solid state within few hours. It fills the lumen in a compact manner and reproducing the shape [7]. Hence both arteries and veins could be studied together.

\section{MATERIALS AND METHODS}

This study was carried out in the Research Laboratory of the Department of Anatomy, JIPMER in collaboration with the Department of Forensic Medicine and Toxicology, JIPMER from June 2015 to June 2017. The study was approved by the Post Graduate Research Monitoring Committee (vide approval No. PGRMC/Anat/01/2015 dated 01.06.2015) and Institute Ethics Subcommittee (Human studies) (vide approval No. JIP/IEC/SC/2015/19/781 dated 17.07.2015).

It was a cross-sectional descriptive study. After getting informed written consent from close relatives of the deceased, fresh adult human heart specimens were collected during autopsy from Department of Forensic Medicine and Toxicology, JIPMER subject to the inclusion and exclusion criteria.

Inclusion criteria: Post-mortem heart specimens of subjects above 20 years of age of both sexes.

Exclusion criteria: Post-mortem heart specimens damaged due to trauma, history of heart surgery, myocardial Infarction, cardiomyopathy, pericarditis.

Sample size was 104 . The procedure was carried out after thorough washing of the fresh specimen under tap water. PU foam media (Soudafoam 1K), was injected after mixing with acetone and colouring reagent. Corrosion was done using $10 \%$ Sodium hydroxide $(\mathrm{NaOH})$. Then the specimen was washed with water to remove the corroded tissue, and cast was allowed to dry. The data was collected and cast photographed.

\section{RESULTS}

Fig. 1: Complete triangle; GCV is related to both the arteries.

Fig. 2: The triangle is open at superior end.

Fig. 3: The triangle is absent.

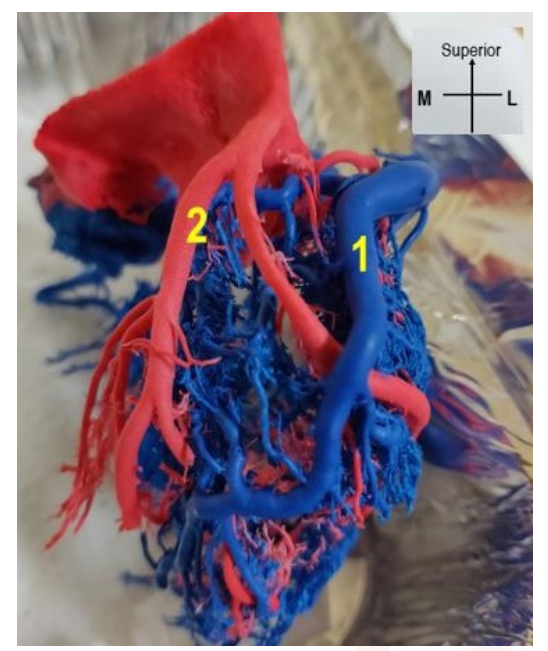

Fig. 4: The triangle is open at inferior end, GCV is at distance from AIA.
Fig. 5: GCV begins to the right of AIA.

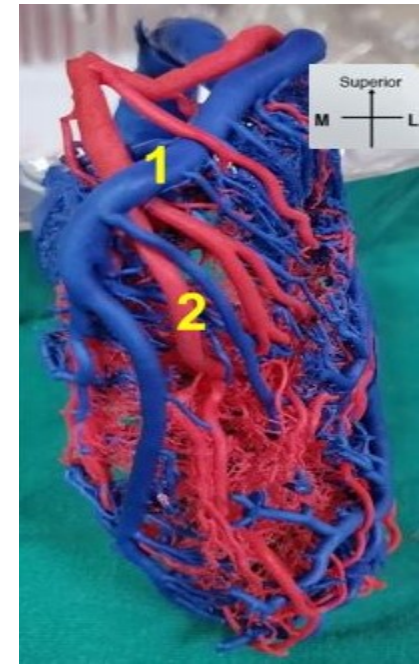

Fig. 6: Intertwined relationship of GCV with the arteries.

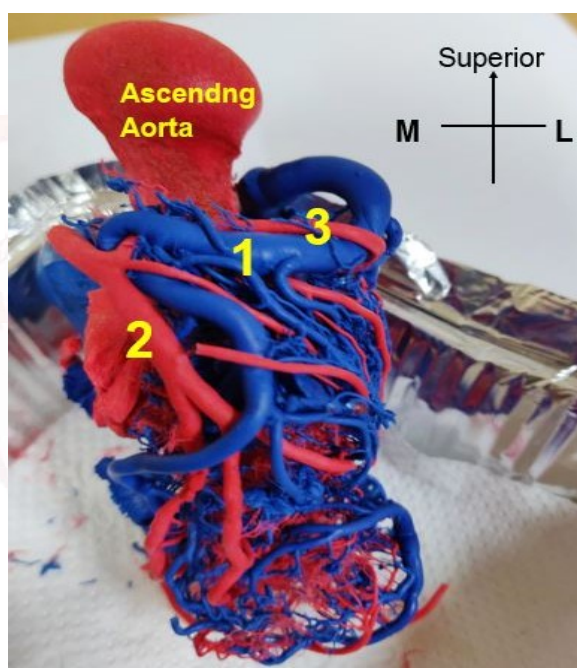

Note: 1- GCV; 2- AIA; 3- CXA. All images were taken in left oblique view.

\begin{tabular}{|c|c|c|c|c|c|c|c|}
\hline \multirow{10}{*}{$\begin{array}{l}\text { Table 1: Comparison } \\
\text { of frequencies of the } \\
\text { types of triangle of } \\
\text { Brocq and Mouchet } \\
\text { across various } \\
\text { studies. }\end{array}$} & & Present Study (2018) & $\begin{array}{c}\text { Ortale } \\
2001[8]\end{array}$ & $\begin{array}{c}\text { Sousa } \\
\text { Rodriguez } \\
2004 \text { [6] }\end{array}$ & $\begin{array}{l}\text { Andrade } \\
2010[1]\end{array}$ & $\begin{array}{c}\text { Bharati } 2013 \\
\text { [9] }\end{array}$ & $\begin{array}{l}\text { Siddharth } \\
2016[10]\end{array}$ \\
\hline & & $\begin{array}{l}\text { South India } \\
\text { (Puducherry, } \\
\text { Tamilnadu) }\end{array}$ & Brazil & Brazil & Brazil & $\begin{array}{l}\text { South India } \\
\text { (Karnataka) }\end{array}$ & North India \\
\hline & Type of study & Corrocion cast & Cadaveric & Cadaveric & Cadaveric & Cadaveric & Cadaveric \\
\hline & Types of triangle & & & & & & \\
\hline & Sample size & 104 & 37 & 26 & 23 & 30 & 30 \\
\hline & Closed & 6.7 & 18 & 35 & 21.7 & 50 & 46.43 \\
\hline & Completely open & 1.92 & 15 & 9 & 17.4 & 6.7 & 10.71 \\
\hline & Inferiorly open & 87.5 & 64 & 52 & 39.1 & 20 & 28.57 \\
\hline & Superiorly open & 0.96 & 3 & 4 & 8.7 & 10 & 14.28 \\
\hline & Absent & 1.92 & - & - & 11.1 & 13.3 & - \\
\hline
\end{tabular}

Table 2: Relationship of great cardiac vein with the arteries forming the triangle compared to previous studies.

\begin{tabular}{|c|c|c|c|c|c|c|}
\hline & Current study & $\begin{array}{c}\text { Von } \\
\text { Ludinghausen } \\
{[11]}\end{array}$ & Pejkovic [5] & Ortale [8] & $\begin{array}{c}\text { El } \\
\text { Maasarany[3] }\end{array}$ & Gerber [12] \\
\hline Left of AIA & 87.51 & 100 & ------- & Majority & ----- & 88 \\
\hline Right of AIA & 8.65 & ----- & Majority & ------- & ----- & ------ \\
\hline Superficial to CXA & 66.34 & 60 & 64 & 73 & 95 & ------- \\
\hline Deep to CXA & 29.82 & 40 & 34 & 22 & 5 & ------ \\
\hline
\end{tabular}


The triangle was present in $98 \%$ of the hearts. Relationship of GCV in triangle of Brocq and Mouchet: As per the classification by SousaRodrigues [6], inferiorly open type of Triangle of Brocq and Mouchet was the most common (87.5\%). Next common type was, closed type (6.7\%). Table 1 gives comparison of the present study with previous ones.

We also classified the relationship of GCV with the arteries based on matrix described by Bales et al [4]. Further sub-divisions were based on proximal or distal crossing as well as, whether the vein crosses superficial or deep to the arteries. (Table 2)

The GCV was to the left of AIA in $87.51 \%$. The vein was superficial to CXA in $66.34 \%$ (proximal crossing-33\%, distal crossing- 33.65\%). The GCV was deep to CXA in $29.82 \%$ (proximal-16.35\%, distal-13.47\%). The vein did not cross both the arteries in $1.92 \%$. The intertwined relationship with arteries was observed in $1.92 \%$ of cases.

\section{DISCUSSION}

The morphology and variants of GCV were studied by Pejkovic et al. (1992) using gelatine and Chinese ink [5]. In their study the triangle was present in $98 \%$. As per classification by SousaRodrigues et al (2004), if the GCV crosses both AIA and CXA, it is closed type. Closed type was seen in majority of specimen. If the GCV is to left of AIVA and crosses CXA distally, then the triangle is open at its right end (open inferiorly). If the vein crosses only AIA, the triangle is open at its left end (open superiorly). The triangle can be open at its right and left end, of the vein doesn't cross any of the arteries- open type $[5,6]$.

In the present study we have tried to describe the course and relationship of GCV in relation to the arteries forming triangle of Brocq and Mouchet. Table 1 gives the comparison of the present study with previous authors (mostly they were cadaveric studies). We carried the study using corrosion cast technique, previous studies were on cadavers. We found that, inferiorly open type of triangle (87\%) was higher in our study, when compared with previous authors. The triangle was closed type in $6.7 \%$.

For the triangle to be placed under closed type, GCV has to be to the right of AIA and cross CXA.
In some, we observed, GCV begins in upper half of anterior interventricular groove. In cadaveric studies in some specimens' anatomy may not be clear, or gets disrupted during dissection. This can explain the difference in frequency of each type in our study as compared to other studies. The current study is corrosion cast based, whereas that in literature are cadaveric studies.

But the relationship of arteries and veins was complex in few specimens. Bales (2004) described the relationship between GCV and left coronary artery branches as intertwined (variant) and non-intertwined (normal) types. Then other varieties have been classified based on: a) initial course related to AIVA- right or left; b) crosses superficial or deep to AIVA; c) proximal or distal crossing of CXA; d) superficial or deep to CXA. He classified these relations in form of a matrix of various possibilities from $A$ to $L$ (based on findings from atlases, textbooks and journal articles). But the frequencies of each variety were not mentioned. In the present study, the different frequencies of such relations of GCV with arteries in the study population was carried out.

Relationship with AIVA: (Table 2) The GCV in relation to AIA has been mentioned by few authors. Von Ludinghausen mentions that in all 350 specimens studied the GCV is to the left of the artery [In contrast, Pejkovic and Bogdanovic (1992) studied 150 hearts and concluded that the initial course of the GCV was to the right of AIVA in most cases; of which $90 \%$ crossed the AIVA superficially and $10 \%$ deeply. In the present study, $87.5 \%$ of specimen showed AIV was left of AIVA, whereas that by Ortale et al, it was in $97 \%$ and Gerber $88 \%$. Bales in literature review, described the GCV coursing superficially or deep to AIVA, and also noted whether this occurs proximally or distally to CXA (Table 2 ).

Relationship with circumflex artery: (Table 2) In the study by Von Lu"dinghausen (1987), the GCVs crossed superûcial in $60 \%$ and $40 \%$ deep to the CXA in $40 \%$; they crossed in proximal position in all these specimens [11]. In the present study, GCV was superficial to CXA in $66 \%$ and in $30 \%$, it was deep. This is similar to findings by previous studies (Pejkovic, Ortale). El Maasarany observed, GCV to be superficial in $95 \%$. 
Bales (2004) in his literature review, describes that the vein can cross CXA proximally or distally [4]. In our study, proximal crossing was observed in $49 \%$ cases (32.69\%- superficial; $16.35 \%$ - deep to CXA), whereas distal crossing of CXA was in 47\% (33.65\%- superficial; $13.47 \%$ deep).

Pejkovic et al. (1992), in describing the triangle of Brocq and Mouchet, noted that in 64\%, GCV crosses CXA proximally; $61 \%$ superficial and $3 \%$ deeply. They also stated that, when GCV crossed AIA superficial position, the vessel had similar relation with CXA. Whereas if GCV is deep to AIA, it was mostly found to cross deep to CXA.

As per Pejkovic, retrograde perfusion of myocardium is being done via coronary sinus. This is possible due to intramyocardial collateral venous circulation. Cardiac veins like GCV can be utilized in diagnosis and therapy of ischemic myocardial lesions [5].

Bales also mentions of a variant wherein, the GCV and CXA have intertwined in coronary sulcus. They opined that the effect of such relationship could be physiological and embryological [4]. In the occlusive diseases of artery, venous return in the GCV may be compromised due to compression by rigid arteries [5]. During non-invasive measurement of GCV flow, non-intertwined course is said to be advantageous. GCV is prone to iatrogenic injury during operations near left auricle, where it is closely related to CXA. Intertwined relationship makes it prone to injuries [4].

GCV is of interest in interventional cardiology. Two scenarios have been described by Gerber et al in this context: a) In coronary artery bypass grafting- arterialization of GCV is done; b) in cases of transvenous placement of pacemakers or defibrillating electrodes, GCV has been utilized. Due to the intertwined relationship of vein with arteries lead placement can be unsuccessful or can lead to perforation [12]. Cazeau et al. reported that pacemaker implantation is successful in $92 \%$, but GCV was preferred when other sites could not be accessed [13].

Gerber suggested that in cases of crossing of AIVA by GCV, were not suitable candidates for percutaneous coronary artery bypass grafting, since the site of overlap can mask the calcification of artery [12].

El Maasarany suggested that the GCV may kink at the site where it is deep to muscular CXA leading to obstruction of lumen. They also noted that GCV is closely related to anterolateral commissure of mitral valve in the triangle of Brocq and Mouchet. Hence at risk during interventional procedures [3].

The triangle of Brocq and Mouchet is helpful when intravascular ultrasound of coronary arteries is carried out. Pericardium, myocardium and vessels in the neighbourhood can be visualized [2]. Variations of this triangle may have implications in detecting these structures by ultrasonography.

\section{CONCLUSION}

The anatomy of great cardiac vein and its variant course is of significance in interventional cardiology procedures. Hence prior identification of the cardiac venous anatomy by radiological studies- CT or MRI is essential. Traditionally five types of arrangement within the triangle has been described. But the relationship between great cardiac vein and the arteries forming the triangle is complex. We came across casts wherein the vein was intertwined in complex manner in relation to both the arteries, and exact configuration of the triangle was absent. This necessitates for more studies to define more accurate way to classify the arrangement of structures in the triangle.

\section{Conflicts of Interests: None}

\section{REFERENCES}

[1]. Andrade FM, Ribeiro DC, Babinski MA, Cisne R, Goes ML. Triangle of Brocq \& Mouchet in Brazilian cadavers and clinical implications. J Morphol Sci. 2010; 27 (3-4), 127-129.

[2]. Metz, Ja., Yock, Pg. And Fitzgerald, PJ. Intravascular ultrasound: basic interpretation. Cardiology Clinics. 1997; 15 (1), 1-15.

[3]. El-Maasarany S, Ferrett CG, Firth A, Sheppard M, Henein MY. The coronary sinus conduit function: anatomical study (relationship to adjacent structures). Europace. 2005; 7(5),475-81.

[4]. Bales GS. Great cardiac vein variations. Clin Anat. 2004; 17(5), 436-43.

[5]. Pejkovic B, Bogdanovic D. The great cardiac vein. Surg Radiol Anat. 1992; 14(1):23-8. 
[6]. Sousa-Rodrigues CF, Alcântara SF.; Silva WNV, Olave E. Arterio-venous trigone of the heart (Brocq \& Mouchet trigone). Int. J. Morphol. 2004; 22(4):291296.

[7]. De Sordi N, Bombardi C, Chiocchetti R, Clavenzani P, Trerè $\mathrm{C}$, Canova $\mathrm{M}$ et al. A new method of producing casts for anatomical studies. Anat Sci Int. 2014; 89:255-65.

[8]. Bharathi D, Sathyamurthy B. An anatomical study of triangle of Brocq \& Mouchet in human cadaveric heart \& its clinical relevance. IOSR-JDMS. 2013; 8(2),12-15.

[9]. Roy SS, Dubey A. Triangle of Brocq and Mouchet: An anatomical study in human cadaveric heart and its clinical significance. Int J Anat Res. 2016; 4(2): 2266-8.

[10]. von Lu"dinghausen M. Clinical anatomy of cardiac veins, Vv. cardiacae. Surg Radiol Anat. 1987; 9,159168.
[11]. Ortale JR, Gabriel EA, Lost C, Marquez C. The anatomy of coronary sinus and its tributaries. Surg Radio Anat. 2001; 23(1), 15-21.

[12]. Gerber TC, Sheedy PF, Bell MR, Hayes DL, Rumberger JA, Behrenbeck T, Holmes DR, Schwartz RS. 2001. Evaluation of the coronary venous system using electron beam computed tomography. Int J Cardiovasc Imaging 17:65-75.

[13]. Cazeau S, Leclercq C, Lavergne T, Walker S, Varma C, Linde $C$ et al. Effects of multisite biventricular pacing in patients with heart failure and intraventricular conduction delay. N Engl J Med. 2001; 344:87380.

\footnotetext{
How to cite this article:

Suma $H$ Y, Shanthini S. RELATIONSHIP OF GREAT CARDIAC VEIN IN THETRIANGLE OF BROCQ AND MOUCHET- A CORROSION CAST STUDY. Int J Anat Res 2019;7(2.1):6437-6442. DOI: 10.16965/ijar.2019.137
} 